\title{
The prevalence of bacterial organisms on toilet door handles in Secondary Schools in Bokkos L. G. A., Jos, Plateau Sate, Nigeria
}

\author{
*Lynn Maori ${ }^{1}$, Vivian Okemena Agbor ${ }^{1}$ and Wasa Alibe Ahmed ${ }^{2}$ \\ ${ }^{I}$ Department of Medical Microbiology, Federal School of Medical Laboratory Sciences Jos, Plateau State, P. \\ M. B2253, Nigeria. \\ ${ }^{2}$ Department of Biological Sciences, Faculty of Science, Gombe State University, P.M.B 127, Gombe, Gombe \\ State, Nigeria
}

\begin{abstract}
The prevalence of bacterial organisms on toilet door handles in secondary schools in Bokkos Local Government; Jos Plateau State, Nigeria was evaluated. This work was carried out in March 2011. A total of 120 samples were collected and cultured for bacterial isolates, 40 from each of the schools (Government Secondary School Bokkos, All Nation Academy and Government secondary School Mushere). The following organisms were isolated Staphylococcus specie 26(43.3\%), Candida specie 6(10\%), Escherichia coli 10(16.7\%), Citrobacter specie 1(1.7\%), Klebsiella specie 12(20\%), Proteus specie 4(6.7\%) and Salmonella specie 1(1.7\%). Out of the 120 samples that were collected $60(50 \%)$ yielded growth and 60 showed no growth at all. The result showed that G. S. S. Bokkos has the highest contamination with a total number of 29(48.3\%) organisms isolated followed by All Nations Academy with 18(30\%) organisms isolated and then G. S. S. Mushere with 13(21\%). The result of this study indicates high prevalence rate of bacteria on toilet door handles in Secondary Schools in Bokkos L. G. A.
\end{abstract}

Key word: Staphylococcus, Candida, Escherichia coli, Citrobacter, Klebsiella, Proteus, Salmonella

\section{Introduction}

Microorganisms are living things ordinarily too small to be seen without magnification, in terms of numbers and range of distribution, microbes are the dominant organisms on earth (Kathleen and Arthur, 2002). A large and diverse group of microscopic organisms that exist as single cells or cell clusters; it also includes viruses, which are microscopic but not cellular (Jawetz et al, 2007).

Prescott $e t a l, 1999$ emphasized that we live in the age of bacteria; they were the first living organism and probably constitute the largest of the earth's biomass. Microbes can be found nearly everywhere, from in the deep in the earth's crust, to the polar ice and oceans, to the bodies of plants and animals. Being mostly invisible, the actions of microorganisms are usually not as obvious or familiar as those of larger plants and animals (Kathleen and Arthur, 2002).

The human body harbours several species of bacteria, viruses, fungi and protozoa. The anatomic sites where bacteria are usually discovered include the skin (Staphylococci and Bacteroides), Oropharynx (Streptococci, Anaerobes), large intestine (Enteric bacilli) and Vagina (lactobacilli), (Beaugerie and Petit, 2004.).

These microorganisms colonizes part of the body without causing infection, these ones are called Normal Body Flora, but can cause infection when found in another site, for example culture of Staphylococcus from a blood sample may represent skin contamination at the time of phlebotomy, the flora of gastro-intestinal tract which are the enterobacterieaceae which are passed out through excreta, is a serious source and reservoirs from which they are transferred to the susceptible host who then becomes possible source of infection, hence making the control of the infection easy.(Francesco Zinzaro, 2010)

Faecal matter remains a major reservoir source of human pathogens, which in adverse situation may bring about outbreaks of infection example shigellosis (Francesco Zinzaro, 2010).

The occurrence of this may be attributed to the unhygienic use of the toilet facilities, which results to the gross contamination of the place including door-handle, which individuals are less likely to see as contaminated (Francesco Zinzaro, 2010).

These articles once contaminated becomes vehicle for transmission of infection, such that the user may succeed in picking this pathogens on his way out even after he/she washed hands, the organism thus picked can introduce infection into such individual either orally or topically or can be transferred to another person. The people exposed to this risk factor are the students, cleaners and teachers e. t. c. who may be unfortunate to come down with the infection, which is in nature in the course of using the toilet (Francesco Zinzaro, 2010). 
The prevalence of bacterial organisms on toilet door handles in Secondary Schools in Bokkos L. G.

\section{Normal Microbial Flora Of The Human Body}

The term microbial flora denotes the population of microorganisms that inhabit the skin and mucus membranes of a healthy normal person (Jawetz et al, 2007). These micro organisms can be grouped into two (Jawetz et al, 2007), the resident flora consists of relatively fixed types of micro organisms regularly found in a given area at a given age, And the transient flora which consist of non pathogenic or potentially pathogenic micro organisms that inhabits the human body for hours, days or weeks (Jawetz et al, 2007). However if the resident flora is disturbed, transient flora may colonize, proliferate and produce disease (Jawetz et al, 2007).

\section{Classification Of Microbial Flora Of The Human Body}

Since most parts of the body at a particular time are different in terms of $\mathrm{pH}$, different organisms are found at sites that are favourable to them (Eckburg et al, 2005).

The classes are as follows:-

1. Normal flora of the Skin:- example are Staphylococcus epidermidis, Diphtheroids, Micrococcus etc(Elizabeth A. Grice et al. 2006);

2. Normal flora of the Nasopharynx:- example $\alpha$-haemolytic Streptococcus, Anaerobic cocci, etc(Eckburg et al, 2005);

3. Normal flora of the Gastrointestinal tract/rectum:- example Enterococci, Non-haemolytic Streptococcus, Diphtheroids etc(Eckburg et al, 2005);

4. Normal flora of the genitalia:- example Corynebacterium, Lactobacillus spp, Non-pathogenic Neisseria spp, Peptostreptococcus etc(Lee P S and Lee K H, 2003).

\section{Kinds Of Interractions Between Microorganisms And Host}

Microbial symbiosis - Living together of two dissimilar organisms, may be divided into different kinds of relationships

a. Mutualism - beneficial to both;

b. Commensalism - beneficial to one; not harmful to the other; Sears C L. (2005).

c. Parasitism - beneficial to one; harmful to the other

(Ann M O'Hara, Fergus Shanahan, 2006).

Factors that Influence the Kind And Number of Microorganisms at Anybody Site Are:

- $\quad$ Availability or unavailability of oxygen;

- $\quad$ Availability of appropriate receptor sites for attachment;

- $\quad \mathrm{pH}$ of the host site;

- $\quad$ The influence exerted by other microorganisms at the site;

- $\quad$ Availability of nutrients;

- $\quad$ The immunological response of the host to the presence of the microbe (Ann M O'Hara, Fergus Shanahan, 2006).

\section{Enterobacteriaeceae}

The enterobacterieaceae is one large family of gram-negative bacteria that exhibit a considerable degree of relatedness (Kathleen and Arthur, 2002). Although many members of this group inhabit the soil, water and decaying matter, they are also common occupant of the large bowel of humans and animals. This group is probably the most common one isolated in clinical specimens - both as normal flora and as an agent of disease example Escherichia coli, Salmonella spp, Proteus spp, Klebsiella, Citrobacter e. t. c.

Members of the group are rod shaped and are typically $1-5 \mu \mathrm{m}$ in length (Dorland's Medical Dictionary, 2010).

\section{Factors Involved in Microbial Flora Infection \\ Individual Susceptibility:}

Important factors influencing acquisition of the infection by micro flora include; immune status, age, underlying disease and therapeutic interventions (Ducel et al, 2002).

Malnutrition, irradiation, indiscriminate use of antibiotics can lower the patient's immunity thereby making them moves vulnerable to the infection (Ducel et al, 2002).

\section{Environmental Factors:}

Microbial flora may contaminate objects and materials, which subsequent contact by a susceptible individual may come down with an infection (Ducel et al, 2002).

These contaminated articles can easily be picked by mere contact and transferred by many students who fail to follow the basic infection control such as washing of hands (Ducel et al, 2002). 
The prevalence of bacterial organisms on toilet door handles in Secondary Schools in Bokkos L. G.

\section{Beneficial Effects of Normal Flora}

The indigenous bacteria of the gastrointestinal tract of an animal, perhaps mainly as a consequence of their great numbers, seen to have the greatest overall impact of their host. Following are the primary beneficial effects of the normal flora that are derived which are:-

- The normal flora synthesize and secrete vitamins

- The normal flora prevent colonization by pathogen

- The normal flora may antagonize other bacteria

- The normal flora stimulate the development of certain tissues

- The normal flora stimulates the production of cross-reactive antibodies (Ann M O'Hara, Fergus Shanahan, 2006).

\section{Detrimental Effects of Normal Flora}

- Bacterial synergism:- Allows an organism to become pathogenic when ordinary it is not

- Opportunistic pathogens:- If host immunity is impaired, normal flora bacteria may cause disease (Ann M O'Hara, Fergus Shanahan, 2006).

\section{Source and Mode of Transmission of infection}

Microorganisms have many sources and reservoirs. The source of microorganisms is the location from which the pathogen is immediately transferred to the host, either directly from the environment or indirectly through an intermediate agent, while reservoir is a site or natural environment in which the pathogen is normally found living and from which infection of the host can occur (Prescott et al, 1999). portal of entry.

Transmission of infection can be referred to as the movement of pathogens from a source to appropriate

The sources and transmission is of different ways which are:-

a) The transient flora of the patient(indigenous infection): Bacteria present as normal flora cause infection because of transmission to site outside the natural habitat (Ducel et al, 2002)

b) Flora from another members of staffs/students(exogenous infection): Bacteria are transmitted between patients:-

i. $\quad$ Through direct contact between patients (e.g. shaking of hands)

ii. Through contaminated objects by the students, or other environmental sources

iii. In the air(dust contaminated with a patients bacteria) (Ducel et al, 2002)

\section{STUDY LOCATION.}

\section{Materials And Methods}

This research was carried out in Three (3) Selected Secondary Schools in Bokkos Local Government, Plateau State, Nigeria.

\section{SAMPLE COLLECTION}

Samples were collected from the toilet door handles using the swab-rinse method of the American Public Health Association as described by Reynolds et al, 2005. Door handles were swabbed with sterile, cotton-tipped applicators (swab stick) moistened with sterile peptone water. It was then introduced into a bijou bottle containing sterile peptone water, shaken, and loosely capped. The bijou bottle were covered with cellophane and transported from Bokkos LGA to Jos University Teaching Hospital and incubated overnight. The rinse fluids were thawed and plated on MacConkey agar, Blood agar and Chocolate agar.

The media used are prepared according to the manufactures prescription.

\section{SAMPLE PROCESSING}

Each collected specimen was processed to identify the bacteria in the sample. The following processing techniques were employed;
a) Culture
b) Motility
c) Gram staining
d) Biochemical test
e) Germ tube

\section{Culture technique}

Each door handle rinsed fluid was aseptically inoculated into the three media namely; MacConkey agar, Blood agar and Chocolate agar. The peptone water in which the door handle swabs were rinsed into, were gently shaken and poured on the media plates and spread evenly over the entire surface of the media using a 
spreader (a sterile bent-glass rod). This was to allow for complete recovery of all organisms picked up in the swab described in 3.2 .

The plates were incubated overnight at $37^{\circ} \mathrm{C}$ (Vandepitte et al., 2003) and examined. Bacterial isolates were first differentiated by macroscopic examination of the colony. The colonies were differentiated based on size, colour, pigmentation, elevation surface texture, and margin, haemolysis on blood and chocolate agar and lactose fermentation on MacConkey.

\section{Gram staining}

Gram staining was done according to method described in Cheesbrough, (2000) was used.

\section{Motility test}

The hanging drop method as described by Barrow and Feltham (1993) was used for further identification of the Gram negative rods seen in 3.4.3. A drop of overnight brought of the bacterial isolates in peptone water was transferred to the centre of a grease-free cover slip with a cooled sterile wire loop. Vaseline was applied at the four corners of the cover-slip. A grease-free microscope slide was placed over the cover slip enough to contact the Vaseline but not with the droplet and the preparation was inverted quickly but smoothly so that the droplet hung below the cover slip. This was observed under X40 objective lens of the microscope under reduced illumination.

\section{Biochemical tests}

\section{Catalase test}

Several biochemical tests were carried out to further identify the various bacteria isolates.

Catalase test was carried out as described by Ochei and Kohlhatkar (2000). A colony of each Gram positive isolate was emulsified in distilled water on a clean grease-free slide placed in a Petri dish. Two drops of hydrogen peroxide were added and observed for effervescence.

\section{Coagulase test}

The slide method as described by Cheesbrough (2000) was used. A drop of normal saline was placed on each end of a clean grease-free slide. A colony of the test isolates was collected with sterile wire loop and emulsified with the drop of normal saline on each end to make two thick suspensions. A loopful of fresh human plasma was dropped on one end of the suspension and mixed gently using a sterile wire loop. The suspension on the other end was left as control. It was observed for clumping. Positive control was set up using staphylococcus aureus.

\section{Oxidase test}

This was carried out using oxidase reagent as described by Baker and Silverton (2001) and Ochei and Kohlhatkar (2000). Two drops of freshly-prepared oxidase reagent (1\% aqueous tetramethyl-P-phenylene diamine hydrochloride solution) was placed on a piece of filter paper. A part of the colony of the bacterial isolate was collected using one end of sterile grease free glass slide and smeared across the filter paper impregnated with the oxidase reagent and observed for deep purple colour within 10 seconds.

\section{Indole test}

This was carried out using Kovac's reagent as described by Baker and Silverton (2001). To a 24 hour culture of the bacteria isolate in peptone water was added $0.5 \mathrm{ml}$ of Kovac's reagent and shaken and examined after a minute for a red colour. Positive control using $E$ coli was set up

\section{Citrate utilisation test}

This was carried with simmon's citrate agar as described by Ochei and Kohlhatkar (2000). A light suspension of the bacteria isolate was made on a normal saline. With a straight sterile wire, the suspension was stab inoculated into the simmon's citrate agar and incubated overnight. This was examined for characteristic blue colour indicating growth. Positive and negative control was set using Klebsiella pneumonia and Escherichia coli.

\section{Urease test}

Christensen's medium was used for this test as described by Ochei and Kohlhatkar (2000). The entire surface of the Christensen's urea slope was inoculated with a suspension of the bacterial isolate and incubated over night and then examined for red pink colour. Positive control was set using Proteus vulgaris and Escherichia coli respectively

\section{Germ tube}

$0.5 \mathrm{ml}$ rabbit serum was pipetted into a small test tube; the colony from the culture plate was inoculated into the serum with a sterile wire loop and was incubated at $35^{\circ} \mathrm{C}$ for 3 hours. A drop of the yeast serum was added onto a glass slide and was covered with a cover slip. It was then examined for sprouting yeast cells with X10 and X40 objectives. (Ochei and Kohlhatkar, 2000). 
The prevalence of bacterial organisms on toilet door handles in Secondary Schools in Bokkos L. G.

\section{Results And Discussion}

40 samples were collected from toilet door handles in All Nations Secondary School in Bokkos L G A, 19(47.5\%) organisms were isolated. 40 samples from G S S Bokkos, 28(70\%) organisms and 40 samples collected from G S S Mushere, 13(32\%) organisms were isolated.

In general a total of 120 samples were collected in this work and $60(60 \%)$ organisms were isolated comprises of 7 different microorganisms.

\section{DESCRIPTION OF THE TABLES}

TABLE 1

This shows the distribution of sampled toilet door-handles and the number of microorganisms isolated from Secondary Schools in Bokkos L G A which are All Nations, G S S Bokkos and G S S Mushere.

Table 1: Distribution of sample toilet door-handles and the number of microorganisms isolated from Secondary Schools in Bokkos L.G.A

$\begin{array}{lllll}\text { All Nation } & 40 & 22 & 18 & 18 \\ \text { G. S. S. Bokkos } & 40 & 10 & 30 & 29\end{array}$

\begin{tabular}{lrrrc}
\hline $\begin{array}{l}\text { Secondary } \\
\text { Schools }\end{array}$ & No. Of Samples. Culture with no & $\begin{array}{c}\text { Culture with Growth. } \\
\text { Growth. }\end{array}$ & $\begin{array}{l}\text { No. Of Organism } \\
\text { Isolated. }\end{array}$ \\
\hline G. S. S. Mushere40 & 120 & 26 & 14 & 13 \\
\hline TOTAL & 120 & 58 & 52 & 60 \\
\hline
\end{tabular}

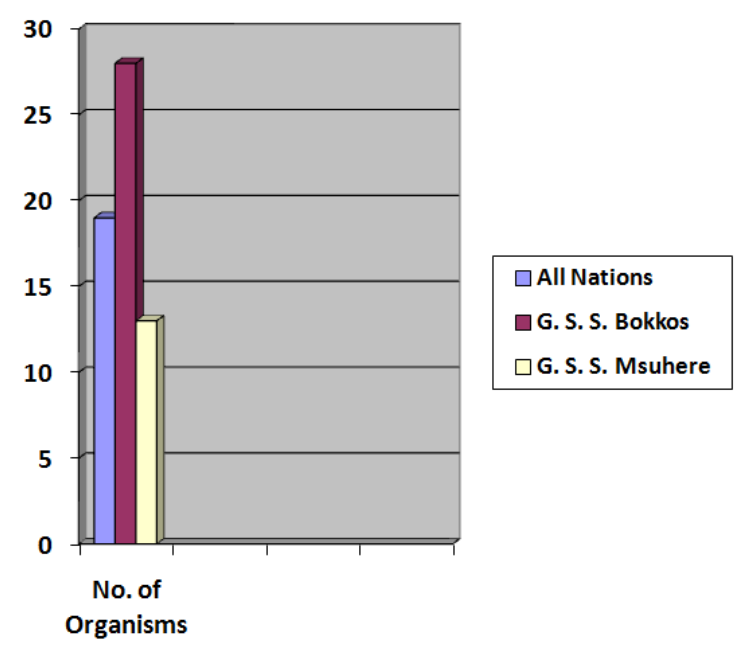

Figure 1: The number of Organisms isolated from the various Schools

TABLE 2: Bacterial count (CFU) and types of microorganisms isolated from the toilet door handles of the Secondary Schools in Bokkos L. G. A.

\begin{tabular}{|c|c|c|c|c|c|c|c|c|}
\hline $\begin{array}{l}\text { Secondary } \\
\text { Schools }\end{array}$ & 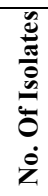 & 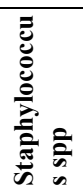 & 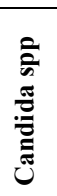 & 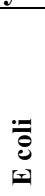 & 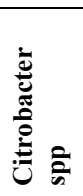 & 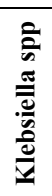 & 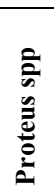 & 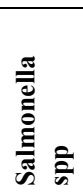 \\
\hline All Nations & 18 & 9 & 3 & 4 & 0 & 2 & 0 & 0 \\
\hline G. S. S. Bokkos & 29 & 13 & 2 & 4 & 0 & 6 & 3 & 1 \\
\hline $\begin{array}{l}\text { G. S. S. S. } \\
\text { Mushere }\end{array}$ & 13 & 4 & 1 & 2 & 1 & 4 & 1 & 0 \\
\hline Total & 60 & 26 & 6 & 10 & 1 & 12 & 4 & 1 \\
\hline
\end{tabular}


The prevalence of bacterial organisms on toilet door handles in Secondary Schools in Bokkos L. G.

TABLE 3: Percentage prevalence of the isolates from the door handles in relation to different Secondary Schools.

\begin{tabular}{|c|c|c|c|c|c|c|c|c|c|}
\hline $\begin{array}{l}\text { Secondary } \\
\text { Schools }\end{array}$ & & 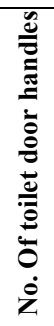 & 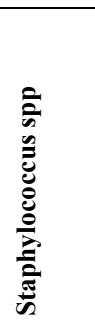 & 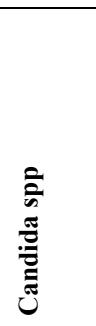 & 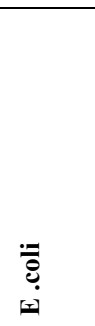 & 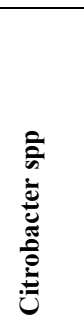 & 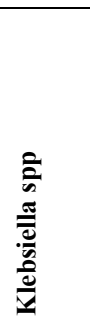 & 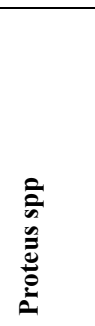 & 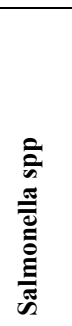 \\
\hline All Nations & & 40 & $50 \%$ & $16.7 \%$ & $22.2 \%$ & 0 & $11.1 \%$ & 0 & 0 \\
\hline $\begin{array}{l}\text { G. S. } \\
\text { Bokkos }\end{array}$ & S. & 40 & $44.8 \%$ & $6.9 \%$ & $13.8 \%$ & 0 & $20.7 \%$ & $10.3 \%$ & $3.4 \%$ \\
\hline $\begin{array}{l}\text { G. S. } \\
\text { Mushere }\end{array}$ & S. & 40 & $30.7 \%$ & $7.7 \%$ & $15.4 \%$ & $7.7 \%$ & $30.7 \%$ & $7.7 \%$ & 0 \\
\hline
\end{tabular}

The percentage prevalence of the organisms isolated from each school is as follows: (In All Nations) Staphylococcus specie 50\%, Candida $16.7 \%$, E coli $22.2 \%$, Citrobacter specie $0 \%$, Klebsiella specie $11.1 \%$, Proteus specie 0\% and Salmonella specie 0\%. In G. S. S. Bokkos Staphylococcus specie 44.8\%, Candida specie $6.9 \%$, E coli 13.8\%, Citrobacter specie 0\%, Klebsiella specie 20.7\%, Proteus specie 10.3\% and Salmonella specie 3.4\%. In G. S. S. Mushere, the percentage prevalence is Staphylococcus specie 30.7\%, Candida specie $7.7 \%$, E coli $15.4 \%$, Citrobacter specie 7.7\%, Klebsiella specie 30.7\%, Proteus specie $7.7 \%$ and Salmonella specie $0 \%$

The total percentage prevalence include: $10 \%$ Candida species, $43.3 \%$ Staphylococcus species, $16.7 \%$ E coli, $6.7 \%$ Proteus species 20\%, Salmonella 1.7\%, Klebsiella species and 1.7\% Citrobacter specie.

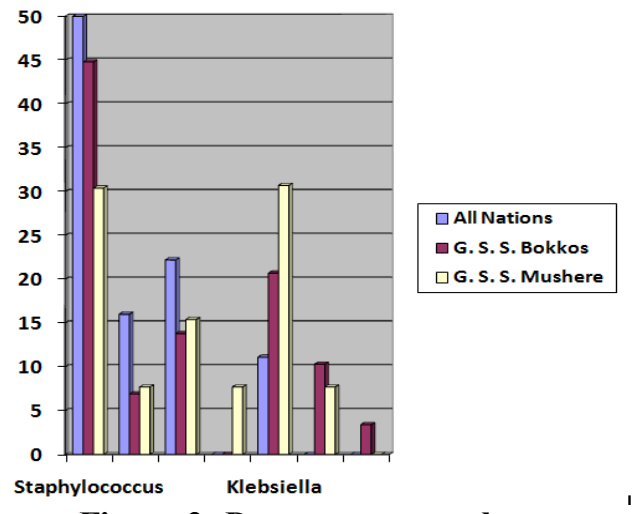

Figure 2: Percentage prevalence

A toilet is a plumbing fixture primarily intended for the disposal of human excreta, urine and faecal matter. Additionally, vomit and menstrual waste are sometimes disposed of in the toilets in some societies.

Toilets are primary made to be a place where individuals ease themselves. It is quite important to also mention that, in addition to the purpose which toilets serves, it can also serves as a serious source on infection ( e.g. Salmonellosis, UTI, GTI etc) especially when the standard of hygiene is very poor because of faecal contamination.

To a very good toilet door, there is a point at which the user opens it (i.e. door-handle) but some might have broken, thus leaving the user at the mercy of using some specific sites. These specific sites can become automatically a reservoir of infection when contaminated since the toilet user must have to touch the point both at entrance and exit from the toilet. Hence, one may pick the pathogen through which he may get him/herself infected or transfer it to another.

The microorganisms isolated from the toilet door-handles at Secondary Schools in Bokkos L G A in their decreasing order of frequency are:-

43.4\%Staphylococcus species, 20\% Klebsiella species, 16.7\% E coli, 10\% Candida species, $6.7 \%$ Proteus species, $1.7 \%$ of both Salmonella and Citrobacter species. This work is in-line with western campus students who carried out an experiment to isolate and identify bacteria on toilet door handles and bathrooms, and find out that the following organisms were present: E coli, S aureus, Streptococcus species, Campylobacter species and Salmonella species, (Baker and Bloomfield, 2000). Sanitary conditions in public places have always been a major problem, especially in the toilet since some organisms are able to survive for weeks and months in dry areas e. g. Staphylococcus species (Baker and Bloomfield, 2000). 
The staphylococcus species isolated in this work yielded growth $26(43.3 \%)$.

E coli $(16.7 \%)$ is a major cause of infection by enterobacteria. It is mostly implicated in urinary tract infection, it is also an indicative of faecal contamination and when consumed results to gastroenteritis and diarrhoea.

Other enterobacteria isolated in this work are Salmonella species (1.7\%), Salmonella causes enteric fever and bacteraemia. Citrobacter species (1.7\%) is an opportunistic organism occasionally isolated from urine, blood and other specimens (Cheesbrough, 2002). Candida species (10\%) is an opportunistic pathogen causing systemic and cutaneous mycosis. It has intrinsic resistance resulting in its lower Pathogenicity and disproportionately affects immunocompromised persons.

Interpreting the results obtained from this work, it is clearly that the samples collected from G S S Bokkos showed the highest contamination with a total number of 29(48.3\%) organisms isolated followed by All Nations with 18(30\%) organisms isolated and then G. S. S. Mushere with 13(21\%).

The result of this work shows contamination on toilet door handles of the Secondary Schools in Bokkos L G A, which involve many varieties of microorganisms. Some of the organisms isolated are human pathogens (e.g. Staphylococcus aureus, Klebsiella species, E coli, Proteus species and Salmonella species) while some are opportunistic pathogen (e.g. Staphylococcus species, Candida species, Citrobacter species).

Most of the gram negative bacilli isolated were of enteric origin suggestive of faecal contamination and can give rise to food borne infections and gastroenteritis. Other infections which the organisms isolated in this work can cause include: U T I's, genital tract infection, respiratory tract infection, skin and wound infection, typhoid fever dysentery, diarrhoea. Seeing how contaminated the toilet door handles of the various Secondary Schools in Bokkos and the number and variety of organisms living there, it calls for an intervention, the students and the staffs, in fact generally all toilet users are at risk of contacting the infection.

\section{Acknowledgments}

We wish to express our sincere gratitude to the staff and management of all the Secondary schools contacted for this study. Not forgetting the Local Education Authority (LEA) Bokkos LGA, Plateau State.

\section{References}

[1]. Ann M O'Hara, Fergus Shanahan The gut flora as a forgotten organ. EMBO reports 7, 688 - 693 (01 Jul 2006$)$

[2]. Baker, J. And Bloomfield S. F. (2000). Survival of Salmonella in bathroom and Toilets in homes. Journal of Applied Microbiology, 89: $137-144$

[3]. Baker J., Silverton R. E., and Pallister C. J. (2001). Introduction to Medical Laboratory Technique $7^{\text {th }}$ Edition

[4]. Barrow, G. J. And Feltham, K. A. (1993). Mini review on Bacterial Motility Detection, Cowan and Steel's Manual for the Identification of Medical Bacteria. www.fspublisher.org/./44.pdf

[5]. Beaugerie L and Petit JC. 2004. Microbial-gut interactions in health and disease. Antibiotic-associated diarrhoea. Best Practice \& Research Clinical Gastroenterology, Volume 18, Issue 2, Pages 337-352. PMID 15123074.

[6]. Dorlands Medical Dictionary: Enterobacteriaceae Available at http://www.mercksource.com/pp/us/cns

[7]. hl dorlands spht.jsp?pg=ppdocs/us/common/dorlands/three/000036660.htm, 2010

[8]. Ducel. G., Fabry J., Nicolle L., Girard R., Perruad M., Priiss A., Sawey T. E., Thuriaux M., and Valnhems P. (2002). Prevention of Hospital Acquired Infection: A practical guide, $2^{\text {nd }}$ Edition. WHO Department of Communicable Disease, Surveillance and Response: $1-9$

[9]. Eckburg P. B., Bik E. M., Benrstein C N (2005) "Diversity of the human Intestine microbial flora" Science 308(5728):1635-8

[10]. Elizabeth A. Grice et al. (2006). "Topographical and Temporal Diversity of the Human Skin Microbiome". Science 324 (5931): 1190-2. doi:10.1126/science. 1171700

[11]. Francesco Zinzaro (2010) http://ezineartides.com? Normal Microbial flora and Id=4121703, April 16, 2010.

[12]. Jawetz, Melnick and Adelberg's (2007). Medical Microbiology $24^{\text {th }}$ Edition, McGraw Hill Publishing Press.

[13]. Kathleen, P. T., and Aurthur Talaro (2002). Foundations in Medical

[14]. Microbiology $4^{\text {th }}$ Edition.

[15]. Lee P. S, Lee K. H (2003). "Escherichia coli--a model system that benefits from and contributes to the evolution of proteomics.". Biotechnol Bioeng 84 (7): 801-14. doi:10.1002/bit.10848. PMID 14708121.

[16]. Monica Cheesbrough 2002). District Laboratory Practice in Tropical Countries Part 2, Cambridge University Press, Low Price Edition.

[17]. Ochie, J. And Kolhatkar, A. (2000). Medical Laboratory Science, theory and practice. Tata McGraw-Hill Publishing Company Limited (New Delhi)

[18]. Prescott L.M., Harley J.P., Klen A. Donald (1999). Microbiology, fourth Edition, McGraw Hill Publishing Press.

[19]. Reynolds. K. A., and Hurst C. J. (2005). Manual of Environmental Microbiology $2^{\text {nd }}$ Annual Public Health Association page 9.

[20]. www.archimer.Ifremer.fr/./1465 pdf

[21]. Sears C L. 2005. A dynamic partnership: Celebrating our gut flora. Anaerobe, Volume 11, Issue 5, Pages 247-251. PMID 16701579.

[22]. Vandepitte, J. (2003). Basic Laboratory Procedure in clinical Bacteriology/ J. Vandepitte (et al) World Health Organisation.

[23]. Geneva. 